\title{
Increased angiotensin-converting enzyme activity in the left ventricle after infarction
}

V.C.W. Busatto ${ }^{1}$, M.A. Cicilini ${ }^{2}$ and J.G. Mill ${ }^{2}$
${ }^{1}$ Departamento de Biologia and ${ }^{2}$ Departamento de Ciências Fisiológicas, Universidade Federal do Espírito Santo, 29040-090 Vitória, ES, Brasil

\section{Correspondence \\ J.G. Mill \\ Departamento de Ciências \\ Fisiológicas, UFES \\ Av. Marechal Campos, 1468 \\ 29040-090 Vitória, ES \\ Brasil \\ Fax: 55 (027) 335-7330}

Research supported by CNPq

(No. 522733/95-6) and FINEP.

......................

Received July 17,1996

Accepted March 5, 1997
Abstract

An increase in angiotensin-converting enzyme (ACE) activity has been observed in the heart after myocardial infarction (MI). Since most studies have been conducted in chronically infarcted individuals exhibiting variable degrees of heart failure, the present study was designed to determine ACE activity in an earlier phase of MI, before heart failure development. MI was produced in 3-month old male Wistar rats by ligation of the anterior branches of the left coronary artery, control rats underwent sham surgery and the animals were studied 7 or 15 days later. Hemodynamic data obtained for the anesthetized animals showed normal values of arterial blood pressure and of end-diastolic pressure in the right and left ventricular cavities of MI rats. Right and left ventricular (RV, LV) muscle and scar tissue homogenates were prepared to determine ACE activity in vitro by measuring the velocity of His-Leu release from the synthetic substrate Hyp-His-Leu. ACE activity was corrected to the tissue wet weight and is reported as nmol His-Leu $\mathrm{g}^{-1} \mathrm{~min}^{-1}$. No significant change in ACE activity in the RV homogenates was demonstrable. A small nonsignificant increase of ACE activity $(11 \pm 9 \%$; $>>0.05)$ was observed 7 days after MI in the surviving left ventricular muscle. Two weeks after surgery, however, ACE activity was $46 \pm 11 \%(\mathrm{P}<0.05)$ higher in infarcted rats compared to sham-operated rats. The highest ACE activity was demonstrable in the scar tissue homogenate. In rats studied two weeks after surgery, ACE activity in the LV muscle

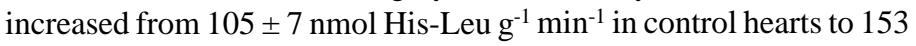

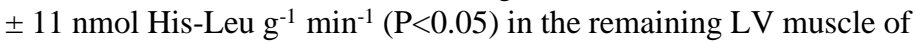
MI rats and to $1051 \pm 208 \mathrm{nmol}$ His-Leu $\mathrm{g}^{-1} \min ^{-1}(\mathrm{P}<0.001)$ in the fibrous scar. These data indicate that ACE activity increased in the heart after infarction before heart failure was demonstrable by hemodynamic measurements. Since the blood vessels of the scar drain to the remaining LV myocardium, the high ACE activity present in the fibrous scar may increase the angiotensin II concentration and decrease bradykinin in the cardiac tissues surrounding the infarcted area. The increased angiotensin II in the fibrous scar may contribute to the reactive fibrosis and hypertrophy in the left ventricular muscle surviving infarction.
Key words

- Angiotensin-converting enzyme

- Myocardial infarction

- Angiotensin II

- Renin-angiotensin system 


\section{Introduction}

Increasing evidence suggests that the renin-angiotensin system (RAS) exerts its influence on the organism not only through its circulating components (the endocrine RAS) but also through several paracrine RAS localized in the brain, heart, blood vessels, and adrenals (1). The specific physiologic roles of these paracrine RAS have not been totally elucidated. However, indirect evidence obtained mainly with the use of RAS inhibitors has suggested that this local metabolism of peptides related to the RAS exerts an important influence on the local circulatory homeostasis, neurotransmission and control of tissue growth processes (2-4). Since all components of the RAS cascade, including the angiotensin-converting enzyme (ACE), have been identified in the heart $(1,5,6)$, we may presume that the concentration of angiotensin II in cardiac tissues is not only dependent on the endocrine RAS but also on the cardiac RAS $(1,6)$. Therefore, changes in the components of the cardiac RAS may influence the local concentration of angiotensin II and bradykinin and thus the physiological activity of these peptides in this organ.

Experimental and clinical evidence has suggested that the local production of angiotensin II may be important for the heart in pathophysiological conditions $(1,6)$. Thus, ACE inhibitors acting on isolated heart preparations reduce the ischemia produced by coronary artery ligation and decrease the incidence of ventricular arrhythmias following reperfusion (7-10). It is likely that these effects are dependent on the inhibition of local angiotensin II generation and/or bradykinin breakdown (11).

Although the extent of activation of the endocrine RAS system is known to depend on arterial blood pressure, blood levels of $\mathrm{Na}^{+}$and $\mathrm{K}^{+}$, and the renal discharge of sympathetic neurons (12), little information is available on the regulation of the paracrine
RAS. Activation of the cardiac RAS has been demonstrated to occur after myocardial infarction $(13,14)$. This activation involves an increased transcription of the gene encoding the ACE mRNA (14-16). The assessment of cardiac RAS, however, has been usually performed in chronically infarcted individuals with variable degrees of heart failure $(13,17)$. Since ACE inhibitors have been used early after infarction, exactly to prevent the postinfarction ventricular remodeling and the development of heart failure (18-20), the present study was designed to determine ACE activity in different regions of the heart during earlier phases of myocardial infarction before the development of heart failure.

\section{Material and Methods}

The experiments were performed in male albino rats, 3 months old at the beginning of the experiment. Myocardial infarction was produced under ether anesthesia according to previously described techniques $(21,22)$. Briefly, thoracotomy was performed at the left fourth intercostal space, the heart was quickly eviscerated and the anterior descending branches of the left coronary artery were ligated with 6-0 mononylon suture between the border of the left atrial appendage and the pulmonary artery outflow tract. After coronary ligation the heart was rapidly returned to its position inside the thoracic cavity and the thoracotomy was closed. Using these procedures, most of the animals developed an antero-lateral transmural infarction covering $20-40 \%$ of the left ventricular surface. The control rats underwent sham surgery. The mortality rate was about $20 \%$, most cases occurring within $30 \mathrm{~min}$ of coronary ligation. After recovery from anesthesia the animals were kept in collective cages (4-5 animals/cage) at the Department animal facility receiving rat chow (Purina) and tap water ad libitum.

One or two weeks later, the rats were 
anesthetized with urethane $(100 \mathrm{mg} / \mathrm{kg}$, ip; Sigma Chemical Co., St. Louis, MO) to insert polyethylene catheters (PE 50) filled with heparinized saline solution $(50 \mathrm{U} / \mathrm{ml})$ into the right jugular vein and carotid artery. The catheters were connected to a pressure transducer (Statham PXL23AA) and advanced into the right and the left ventricular cavities, respectively, to record ventricular pressures. The pulsating arterial blood pressure was recorded in the ascending aorta. The pressure signals were amplified (Funbec MP 100) and recorded on a chart recorder (Funbec RG 300). The intraventricular diastolic pressures were measured in records obtained at $100 \mathrm{~mm} / \mathrm{s}$ and $2 \mathrm{mmHg} / \mathrm{mm}$. The hemodynamic data for each animal were computed from the mean value obtained from eight to ten consecutive cardiac cycles recorded under regular cardiac rhythm.

After acquisition of the hemodynamic data, the rats were killed by decapitation and the heart was rapidly excised and perfused through the aortic stump in a Langendorff apparatus to remove blood from coronary circulation and cardiac cavities. The right and left ventricles were separated, blotted and weighed, the interventricular septum being considered as part of the left ventricle. In the infarcted hearts the scar tissue was carefully dissected from the remaining muscle, blotted and weighed separately. The outlines of both ventricular fragments were drawn on graph paper to obtain their respective areas. The infarct size is reported as percent of the left ventricular endocardial surface covered with a transmural scar (22). The evaluation of the infarct size by this method was recently compared with the classical histological methods, giving similar results (15).

ACE activity was determined in the right and left ventricular muscle and in the scar tissue separately. The tissue fragments were minced into small pieces and homogenated mechanically in a glass homogenizer (GlaCol Mod 099C-K44) at 3,000 rpm in the presence of a 1:5 (w/v) buffered solution of $50 \mathrm{mM}$ sodium borate prepared in $32 \mathrm{mM}$ sucrose, $\mathrm{pH} 7.4$. The homogenates were centrifuged at $1000 \mathrm{~g}$ for $5 \mathrm{~min}$ and the resulting supernatants were stored at $-22^{\circ} \mathrm{C}$ until enzyme assay. ACE activity in the homogenates was determined by a fluorimetric method described by Friedland and Silverstein (23) and modified by Santos et al. (24). Briefly, $100 \mu$ of the homogenate samples of each cardiac fragment was incubated for $10 \mathrm{~min}$ at $37^{\circ} \mathrm{C}$ in $2 \mathrm{ml}$ of the buffered solution containing $5 \mathrm{mM}$ of a synthetic substrate for ACE, Hyp-His-Leu (Sigma). The dipeptide His-Leu released by the reaction was measured fluorimetrically using 365 $\mathrm{nm}$ excitation and 495-nm emission (Hitachi Fluorimeter F-2000). Standard curves for His-Leu concentrations $(0-40 \mathrm{nmol} / \mathrm{ml})$ were used to relate the fluorescence to the amount of His-Leu liberated in the hydrolysis reaction mediated by ACE. ACE activity is reported as nmol of His-Leu released per minute of incubation. All values were corrected to the original wet weight of the tissue samples.

Results are reported as means \pm SEM. The Student $t$-test for independent samples was used to compare two means. One-way analysis of variance (ANOVA) was used to assess differences between more than two means. Intergroup comparisons were obtained with the Tukey test. Regression lines were calculated according to the least squares method. Statistical significance was set at the $95 \%$ level.

\section{Results}

Table 1 shows the weights of the ventricular chambers and the values of the hemodynamic measurements obtained from the groups of rats studied one or two weeks after surgery. The mean infarction sizes of the two groups were similar $(32 \pm 3 \%$ and $30 \pm 2 \%$, respectively; $\mathrm{P}>0.05$ ), with most of the individual values being in the $20 \%$ to $40 \%$ range, indicating medium-size infarcts (21). No 
Table 1 - Weights of the ventricular chambers and hemodynamic data recorded in sham-operated control (Con) and infarcted (Inf) groups of rats.

BW, Body weight; RVW, right ventricle weight; LVW, left ventricle weight; RVEDP, right ventricle end-diastolic pressure; RVSP, right ventricle systolic pressure; LVEDP, left ventricle end-diastolic pressure; LVSP, left ventricle systolic pressure; MAP, mean arterial pressure; HR, heart rate; N, number of rats. In the Inf group, the LV weight corresponds only to the weight of the surviving LV muscle. The infarct size is expressed as the percentual area of the left ventricular surface covered by the scar tissue. Data are reported as means \pm SEM. ${ }^{*} \mathrm{P}<0.05 v s$ Con (Student $t$-test).

\begin{tabular}{|c|c|c|c|c|}
\hline & \multicolumn{2}{|c|}{7 Days } & \multicolumn{2}{|c|}{15 Days } \\
\hline & $\begin{array}{c}\text { Con } \\
(N=10)\end{array}$ & $\begin{array}{c}\operatorname{Inf} \\
(N=13)\end{array}$ & $\begin{array}{l}\text { Con } \\
(N=9)\end{array}$ & $\begin{array}{c}\operatorname{lnf} \\
(N=16)\end{array}$ \\
\hline $\mathrm{BW}(\mathrm{g})$ & $216 \pm 8$ & $229 \pm 10$ & $226 \pm 5$ & $268 \pm 7$ \\
\hline $\mathrm{RVW}$ (mg) & $119 \pm 4$ & $122 \pm 8$ & $123 \pm 3$ & $133 \pm 8$ \\
\hline LVW (mg) & $494 \pm 10$ & $364 \pm 22^{*}$ & $575 \pm 16$ & $455 \pm 19^{*}$ \\
\hline $\mathrm{RVEDP}(\mathrm{mmHg})$ & $3 \pm 1$ & $4 \pm 0.5$ & $5 \pm 1$ & $8 \pm 1$ \\
\hline $\mathrm{RVSP}(\mathrm{mmHg})$ & $28 \pm 2$ & $27 \pm 2$ & $29 \pm 1$ & $33 \pm 2$ \\
\hline LVEDP $(\mathrm{mmHg})$ & $6 \pm 1$ & $8 \pm 1$ & $6 \pm 1$ & $9 \pm 1$ \\
\hline LVSP (mmHg) & $116 \pm 5$ & $107 \pm 5$ & $109 \pm 5$ & $113 \pm 4$ \\
\hline MAP $(\mathrm{mmHg})$ & $83 \pm 4$ & $87 \pm 2$ & $87 \pm 4$ & $92 \pm 3$ \\
\hline HR (bpm) & $367 \pm 13$ & $353 \pm 18$ & $311 \pm 10$ & $314 \pm 11$ \\
\hline Infarct size (\%) & - & $32 \pm 3$ & - & $30 \pm 2$ \\
\hline
\end{tabular}
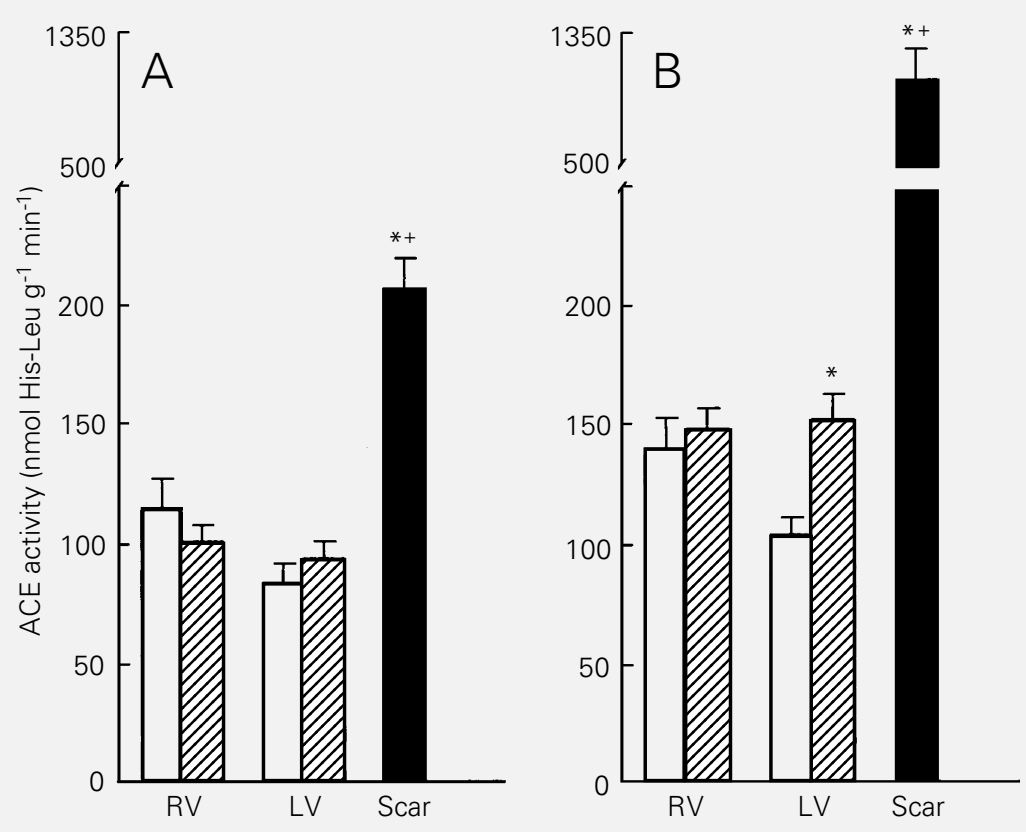

Figure 1 - Angiotensin-converting enzyme (ACE) activity in the right ventricular free wall (RV) and in the left ventricle muscle (LV) of sham-operated control (open bars) and infarcted rats studied 7 (panel A) or 15 (panel B) days after coronary artery occlusion or sham surgery. In the infarcted groups, ACE activity was assayed separately in the surviving left ventricular muscle (hatched bars) and in the scar tissue (closed bars). Observe the great increase in ACE activity in the scar tissue 15 days after infarction. Data are reported as means \pm SEM. $N$ is the same as in Table 1. ${ }^{*} \mathrm{P}<0.05$ vs control group; ${ }^{+} \mathrm{P}<0.001$ vs surviving left ventricular muscle. evidence of right ventricular hypertrophy, which strongly indicates development of heart failure, was observed. In both groups of infarcted animals the left ventricular weight was smaller than in the sham-operated controls. This reduction is due to the fact that the weight of the fibrous scar is less than the weight of the original muscle that it replaces. Hypertrophy of the surviving muscle in the left ventricles, however, is probably occurring because of the difference in left ventricle weight to body weight ratio between the control and infarcted groups, which was about $30 \%$ one week after coronary ligation $(2.29 \mathrm{mg} / \mathrm{g}$ and $1.59 \mathrm{mg} / \mathrm{g}$, respectively) and decreased to only $18 \%$ two weeks after infarction $(2.08 \mathrm{mg} / \mathrm{g}$ and $1.70 \mathrm{mg} / \mathrm{g})$. The arterial and intraventricular pressures recorded in the anesthetized animals showed that the measurement of ACE activity was obtained in hemodynamically compensated animals, since the end-diastolic pressures in both ventricles of the infarcted animals, although slightly elevated, were still within normal limits (Table 1). The absence of right ventricular hypertrophy was also an indirect evidence that the animals were studied before heart failure development.

ACE activity measured in the hearts of sham-operated and infarcted rats is shown in Figure 1. In control rats, ACE activity was significantly higher $(\mathrm{P}<0.05)$ in the right ventricle than in the left ventricle in both groups. In the group studied two weeks after sham surgery, for example, ACE activity was $141 \pm 13$ nmol His-Leu g ${ }^{-1}$ min $^{-1}$ in the right ventricular free wall and $105 \pm 7 \mathrm{nmol}$ His-Leu $\mathrm{g}^{-1} \mathrm{~min}^{-1}(\mathrm{P}<0.05)$ in the left ventricle. This difference between the ventricular chambers was not observed after infarction because ACE activity in the remaining left ventricular muscle increased after infarction whereas it remained relatively stable in the right ventricle. Two weeks after infarction ACE activity was significantly higher in the remaining left ventricular muscle than in the control left ventricle (infarcted $=153 \pm$ 
11 and control $=105 \pm 7$ nmol His-Leu g ${ }^{-1}$ $\left.\mathrm{min}^{-1} ; \mathrm{P}<0.05\right)$.

The highest ACE activity in the infarcted hearts was found in the scar tissue (Figure 1). One week after infarction, ACE activity in the scar tissue was 2.2 times that of the surviving muscle. Two weeks after infarction the ratio of ACE activity between the scar tissue and the surviving left ventricular muscle was almost 7 (left ventricular muscle $=153 \pm 11$ and scar tissue $=1051 \pm 208 \mathrm{nmol}$ His-Leu g ${ }^{-1} \min ^{-1} ; \mathrm{P}<0.001$ ).

A linear and positive correlation between infarct size and ACE activity in the surviving left ventricular muscle and in the scar tissue was observed 7 days after infarction (Figure 2 ). In the group of animals studied two weeks after infarction, weaker correlation coefficients were observed both in the surviving left ventricular muscle $(r=0.50)$ and in the fibrous scar $(r=0.55)$. A higher dispersion of the data found in this group may have contributed to this finding. There were also linear and positive correlations between ACE activity in the scar and in the left ventricular muscle at $7(\mathrm{r}=0.56)$ and 15 days $(\mathrm{r}=0.62)$ after infarction.

\section{Discussion}

The most important finding of the present study was to show that ACE activity increases significantly in the left ventricle after infarction before the development of hemodynamic signals of heart failure. Previous studies have also shown this increase $(13,17)$ but were performed during later infarction phases when some degree of heart failure is usually present. Our results also confirm previous observations obtained by immunohistochemical techniques showing that the increase in ACE activity in the infarcted left ventricle is mainly dependent on the extremely large amounts of activity in the scar tissue $(17,25,26)$. Thus, our results suggest that the scar tissue represents the most important source of increased angio- tensin II activity in infarcted hearts. In the hearts studied two weeks after infarction, the scar tissue contained roughly $60 \%$ of the total ACE activity measured in the whole left ventricle. Since ACE also inactivates bradykinin (1), an impairment of the effects of this peptide in the infarcted heart can also be expected. Therefore, our data suggest an increased content of angiotensin II and a decreased content of bradykinin in the blood draining the fibrotic scar.

The changes of the RAS after infarction are relatively complex. A small and transient activation of the endocrine RAS occurs after myocardial infarction, consequent to an increased synthesis of renin in the kidneys (25). This activation seems to depend on the decrease of cardiac output and blood pressure as well as on the reflex activation of the sympathetic nervous system observed under

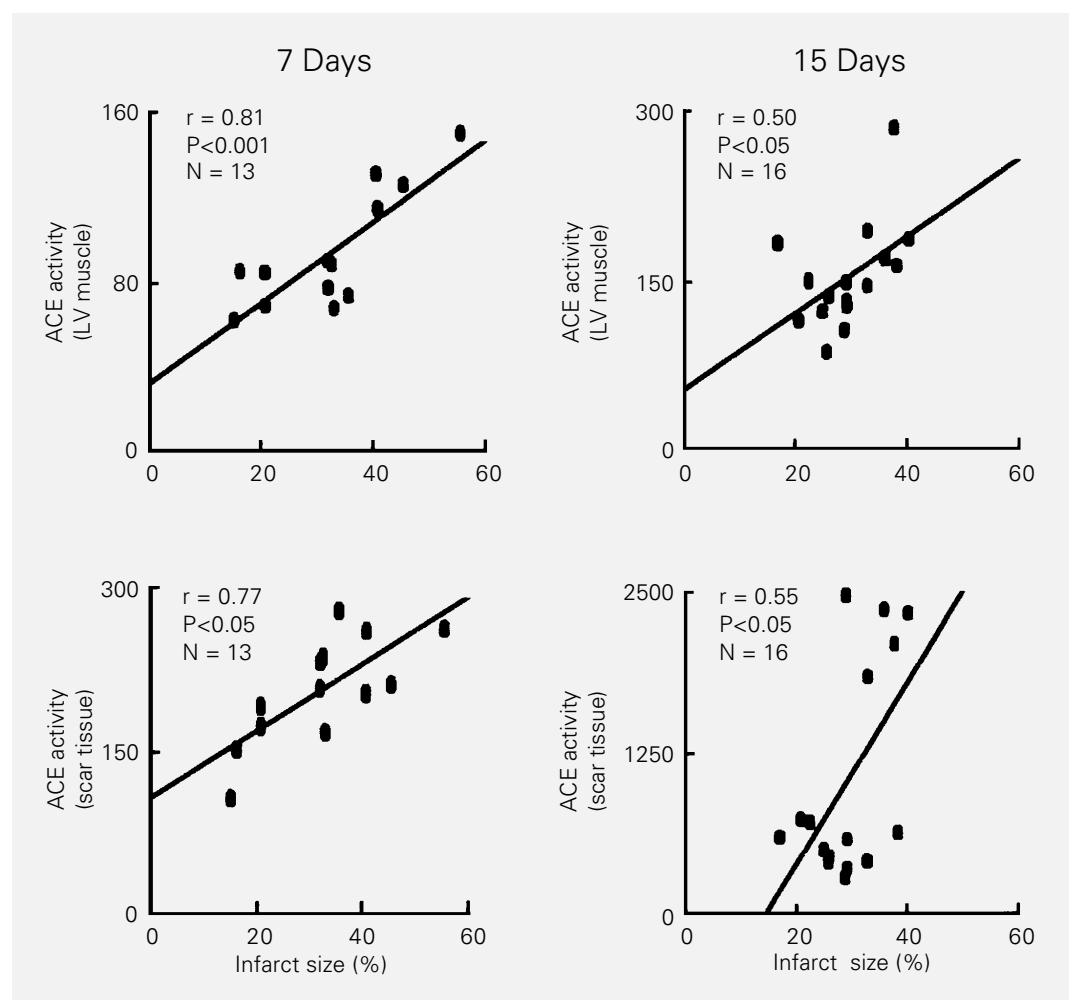

Figure 2 - Relationships between the infarct size and the angiotensin-converting enzyme (ACE) activity in the surviving left ventricular (LV) muscle (upper panels) and in the fibrotic scar (lower panels) of rats studied 7 or 15 days after myocardial infarction. ACE activity is reported as $\mathrm{nmol}$ His-Leu $\mathrm{g}^{-1} \mathrm{~min}^{-1}$. The regression lines were calculated by the least squares method. $r=$ Pearson's correlation coefficient. 
such conditions $(1,12,27,28)$. This activation of the systemic RAS is part of the neuroendocrine response of the organism to myocardial infarction $(1,28)$. In general, normalization of the circulating levels of angiotensin II is attained as normal blood pressure values are recovered. A reactivation of the endocrine RAS may occur later on if heart failure develops (25).

The changes of the cardiac RAS after infarction have not been studied as extensively. Hokimoto et al. (17), using immunohistochemical techniques, found an increased ACE density in explanted hearts from infarcted patients in an advanced phase of heart failure. ACE labeling was increased mainly in the left ventricle muscle, and similar to our findings in the rat, the highest ACE density was also found in the fibrous scar. However, the separation of possible changes of the cardiac RAS secondary to infarction from those due to heart failure is difficult in humans. Thus, experiments conducted on infarcted animals may contribute to the elucidation of this question.

The first study on this subject was performed using the rat model of infarction and an increased ACE activity, corrected to the tissue weight, was demonstrated in the whole left ventricle and in the right ventricle free wall (13). More recent studies using immunohistochemical techniques have shown that this increase in ACE activity is consequent to the increase of ACE staining density in the chronically infarcted left ventricle $(17,26)$. All of these findings, however, were obtained in chronically infarcted animals with some degree of heart failure. The presence of right ventricular hypertrophy in the animals studied by Hirsch et al. (13), for instance, strongly suggests that ACE activity was assayed in hearts taken from animals when heart failure was already present. The purpose of the present study was to separate the changes in ACE activity secondary to infarction from those resulting from heart failure. On this basis, ACE assays were per- formed early after infarction before heart failure development. However, a precise assessment of heart function is more difficult in anesthetized animals. Since our hemodynamic measurements were recorded under urethane anesthesia, we cannot evaluate precisely the extent of hemodynamic impairment produced by infarction in each individual animal. However, the absence of right ventricular hypertrophy despite a small increase in the end-diastolic pressures of both ventricles is a clear indication that the animals used in our study were still in a compensated hemodynamic state. Clear hemodynamic evidence of heart failure development is easily detected later after infarction in rats with infarct of similar size to those used in our study $(29,30)$. Therefore, our results indicate that ACE activity in the infarcted heart increases as part of the response of this organ to infarction, and not as a consequence of the hemodynamic decompensation resulting from the loss of left ventricular contractile mass.

The increased ACE activity after infarction seems to be secondary to the activation of genes encoding this enzyme. Elevated levels of ACE mRNA were found in the heart one month after infarction in rats $(16,17)$. The factors responsible for this genic activation, however, are unknown. Since the wall stress imposed on the cardiac chambers may activate several genes related to the development of myocardial hypertrophy (31) and ACE activity in the infarcted left ventricle is proportional to the infarct size (13), the increased wall stress produced by left ventricular dilation could explain the ACE activation in chronically infarcted individuals in the presence of heart failure. In our study, however, we observed a significant positive and linear correlation between infarct size and ACE activity in surviving left ventricular muscle in the presence of normal values of end-diastolic pressure and probably before a significant ventricular enlargement. Interestingly, the best correlation 
coefficients were found 7 days after infarction. Therefore, we cannot rule out other factors also related to infarct size involved in the activation of the genes encoding ACE in the heart. This possibility could be evaluated by measuring mRNA for ACE and renin from the time of infarct up to 1 month later, as described by Smits et al. (16) and Hokimoto et al. (17) for ACE mRNA.

Weaker correlation coefficients were found between ACE activity in the scar and infarct size. This is probably due to the fact that ACE distribution in the fibrous scar, as demonstrated by immunohistochemistry techniques, is non-uniform. The enzyme density is higher in the outer border of the scar than in the central region $(25,26)$. Two hypotheses could explain these findings. Since the scar tissue is stiffer than the surrounding muscle (32), a higher degree of stress may exist in the transition region between the fibrous scar and the ventricular muscle. The higher degree of hypertrophy close to the scar compared to remote regions of the left ventricle reinforces this view (33). Alternatively, the activity of the enzyme in different regions of the scar may be related to differences in capillary density. ACE is mainly expressed in endothelial cells of blood vessels (26). In infarcted hearts ACE seems also to be expressed in inflammatory cells, mainly macrophages, and in fibroblast-like cells probably derived from smooth muscle cells (26). An increased density of these cells may produce a precocious increase of ACE density in the transition region of infarction. This increase may not depend on infarct size but rather on the intensity of the inflammatory response and blood vessel proliferation following coronary occlusion. Our data, however, do not provide relevant informa- tion on this possibility.

Whatever the underlying mechanism, the increase in ACE activity in the scar may represent an important change in normal peptide metabolism in the heart, suggesting that the blood that drains the infarcted scar may have higher angiotensin II concentrations and lower bradykinin and substance $\mathrm{P}$ concentrations. Angiotensin II acting directly on coronary vessels produces potent constriction. Additionally, this peptide also facilitates norepinephrine liberation from sympathetic endings, potentiating the direct vasoconstrictor effect of this peptide $(2,12)$. Since increased ACE activity tends to decrease bradykinin concentration and hence its vasodilating effect, we may speculate that the increased ACE activity in the fibrotic scar represents a harmful condition for the surrounding myocardium. In this case the tissues localized in the border zone may be submitted to a chemical environment which potentially facilitates the development of hypoxia, arrhythmias and contractile disturbances. Several studies have demonstrated the protective effect of ACE inhibitors for infarcted patients, preventing recurrent myocardial hypoxia, reinfarction and sudden death (18-20). The mechanisms responsible for the beneficial effects of such drugs are not fully explained, but they may also depend on the local inhibition of the RAS, restoring a normal balance between vasoconstrictor and vasodilator peptides generated in the infarcted left ventricle.

\section{Acknowledgment}

The authors would like to thank Maria da Glória de Souza Gomes for helpful technical assistance. 


\section{References}

1. Lindpaintner K \& Ganten D (1991). The cardiac renin-angiotensin system: an appraisal of present and experimental and clinical evidence. Circulation Research, 68: 905-921.

2. Ziang J, Linz W, Becker $H$, Ganten D, Lang RE \& Schölkens B (1984). Effects of converting enzyme inhibitors ramipril and enalapril on peptide action and sympathetic neurotransmission in the isolated rat heart. European Journal of Pharmacology, 113: 215-223.

3. Re RN (1994). The renin-angiotensin system as a growth regulator in cardiovascular and non-cardiovascular tissues. In: Lindpaintner K \& Ganten D (Editors), The Cardiac Renin-Angiotensin System. Futura Publishing Co., Armonk, NY, 141152.

4. Allen IS, Cohen NM, Dhallan RS, Gaa ST, Lederer WJ \& Rogers TB (1988). Angiotensin II increases spontaneous contractile frequency and stimulates calcium current in cultured neonatal rat heart myocytes: insights into the underlying biochemical mechanisms. Circulation Research, 62: 524-534.

5. Dostal DE, Rothblum KC, Chermin MI, Cooper GR \& Baker KM (1992). Intracardiac detection of angiotensinogen and renin: evidence for a localized renin-angiotensin system in neonatal rat heart. American Journal of Physiology, 263: C828-C850.

6. Dostal DE, Booz GW \& Baker KM (1994). The cardiac renin-angiotensin system: an overview. In: Lindpaintner K \& Ganten D (Editors), The Cardiac Renin-Angiotensin System. Futura Publishing Co., Armonk, NY, 1-20

7. Daniell HB, Carson RR, Ballard KD, Thomas GR \& Privitera PJ (1984). Effects of captopril on limiting infarct size in conscious dogs. Journal of Cardiovascular Pharmacology, 6: 1043-1047.

8. van Gilst WH, de Graeff PA, Wasseling H \& de Langen CDJ (1986). Reduction of reperfusion arrhythmias in the ischaemic isolated rat heart by angiotensin converting enzyme inhibitors: a comparison of captopril, enalapril and HOE 498. Journal of Cardiovascular Pharmacology, 8: 722728.

9. Li K \& Chen X (1987). Protective effect of captopril and enalapril on myocardial ischemia and reperfusion damage of rat. Journal of Molecular and Cellular Cardiology, 19: 909-915.
10. Fleetwood G, Boutinet S, Meier M \& Wood JM (1991). Involvement of the renin-angiotensin system in ischemic damage and reperfusion arrhythmias in the isolated perfused rat heart. Journal of Cardiovascular Pharmacology, 17: 351-356.

11. Linz W, Schölkens BA \& Kaiser J (1989). Cardiac arrhythmias are ameliorated by local inhibition of angiotensin formation and bradykinin degradation with the converting enzyme ramipril. Cardiovascular Drugs and Therapy, 3: 873-882.

12. Peach MJ (1977). Renin-angiotensin systems: biochemistry and mechanisms of action. Physiological Reviews, 57: 313370.

13. Hirsch AT, Talsness CE, Heribert S, Paul M \& Dzau VJ (1991). Tissue-specific activation of cardiac angiotensin converting enzyme in the experimental heart failure. Circulation Research, 69: 475-482.

14. Finckh M, Hellmann W, Ganten D, Furtwangler A, Allgeier J \& Boltz $M$ (1991). Enhanced cardiac angiotensin gene expression and angiotensin converting enzyme activity in tachypacing-induced heart failure in rats. Basic Research in Cardiology, 86: 303-316.

15. Lindpaintner $K$, Lu W, Niedermajer $N$, Schieffer B, Just H, Ganten D \& Drexler H (1993). Selective activation of cardiac angiotensinogen expression in post-infarction ventricular remodeling in the rat. Journal of Molecular and Cellular Cardiology, 25: $133-143$

16. Smits JFM, van Krimpen C, Shoemaker RG, Cleutjens JPM \& Daemen MJAP (1992). Angiotensin II receptor blockade after myocardial infarction in rats: effects of hemodynamics, myocardial DNA synthesis, and interstitial collagen content. Journal of Cardiovascular Pharmacology, 20: 772-778.

17. Hokimoto S, Yasue H, Fujimoto K, Sakata $R$ \& Miyamoto $E$ (1995). Increased angiotensin converting enzyme activity in left ventricular aneurysm of patients after myocardial infarction. Cardiovascular Research, 29: 664-669.

18. Nabel EG, Topol EJ \& Galeana A (1991). A randomized placebo controlled trial of combined early intravenous captopril and recombinant tissue-type plasminogen activator therapy in acute myocardial infarction. Journal of the American College of Cardiology, 17: 467-473.
19. Swedberg K, Held P \& Kjekshus J (1992). Effects of the early administration of enalapril on mortality in patients with acute myocardial infarction: results of the Cooperative New Scandinavian Enalapril Survival Study II (CONSENSUS II). New England Journal of Medicine, 327: 678684.

20. Pfeffer JM, Fischer TA \& Pfeffer MA (1995). Angiotensin-converting enzyme inhibition and ventricular remodeling after myocardial infarction. Annual Review of Physiology, 57: 805-826.

21. Pfeffer MA, Pfeffer JM, Fishbein MC, Fletcher PJ, Spadaro J, Kloner RA \& Braunwald E (1979). Myocardial infarct size and ventricular function in rats. Circulation Research, 44: 503-512.

22. Mill JG, Stefanon I, Leite CM \& Vassallo DV (1990). Changes in performance of the surviving myocardium after left ventricular infarction in rats. Cardiovascular Research, 24: 748-753.

23. Friedland J \& Silverstein E (1977). Sensitive fluorimetric assay for serum angiotensin converting enzyme with the natural substrate angiotensin. American Journal of Clinical Pathology, 58: 225-228.

24. Santos RAS, Brum JM, Brosninhan KB \& Ferrario CM (1990). The renin-angiotensin system during acute myocardial ischemia in dogs. Hypertension, 15 (Suppl I): I.121I.127.

25. Hirsch AT \& Dzau VJ (1990). Tissue reninangiotensin systems in the pathophysiology of heart failure. In: Brachmann J, Dietz R \& Kubler W (Editors), Heart Failure and Arrhythmias. Springer-Verlag, Heidelberg, 33-42.

26. Falkenhahn M, Franke F, Bohle RM, Zhu Y, Strauss HM, Bachman S, Danilov S \& Unger $T$ (1995). Cellular distribution of angiotensin-converting enzyme after myocardial infarction. Hypertension, 25: 219226.

27. Watkins IJ, Burton JA, Haber E, Cant JR, Smith FM \& Barger AC (1976). The reninangiotensin-aldosterone system in congestive heart failure in conscious dogs. Journal of Clinical Investigation, 57: 16061617.

28. Dzau VJ, Colucci WS, Hollenberg NK \& Williams GH (1981). Relation of the reninangiotensin-aldosterone system to clinical state in congestive heart failure. Circulation, 63: 645-651. 
29. Bech $P$, Kahr O, Diamant $B$ \& Steiness $E$ (1989). Time course of functional deterioration after coronary artery ligation in rats. Cardiovascular Research, 23: 649-654.

30. Mill JG, Gomes APV, Carrara AB, Gomes MGS \& Vassallo DV (1994). Influence of chronic captopril therapy on the mechanical performance of the infarcted rat heart. Pharmacological Research, 29: 77-88.
31. Kent RL \& McDermott PJ (1996). Passive load and angiotensin II evoke differential responses of gene expression and protein synthesis in cardiac myocytes. Circulation Research, 78: 829-838.

32. Litwin SE, Litwin CM, Raya TE, Warner AL \& Goldman S (1991). Contractility and stiffness of noninfarcted myocardium after coronary ligation in rats. Effects of chronic angiotensin converting enzyme. Circulation, 83: 1028-1037.
33. Cox MM, Berman I, Meyerburg RJ, Smets MJD \& Koslovskis PL (1991). Morphometric mapping of regional myocyte diameters after healing of myocardial infarction in rats. Journal of Molecular and Cellular Cardiology, 23: 127-135. 